\title{
Educação e direitos humanos para mulheres muçulmanas
}

Allana de Freitas Lacerda

Francisca Geny Lustosa

RESUMO: $O$ artigo discute $\mathrm{O}$ direito à educação das mulheres de comunidades islâmicas e sua expressão de universalidade, no âmbito dos direitos humanos. As informações são fruto de uma investigação qualitativa (bibliográfica, documental e de campo), no ano de 2017. Os resultados evidenciam a presença de fatores econômicospolíticos-culturais-religiosos como impedidores e/ou favorecedores do usufruto do direito educacional, além de circunstâncias de guerra/ territórios em perigo, condição sócioeconômica e/ou regras sociais/religiosas ainda arraigadas.

PALAVRAS-CHAVE:

Muçulmana. Educação. Humanos. Discriminação.
Mulher Direitos

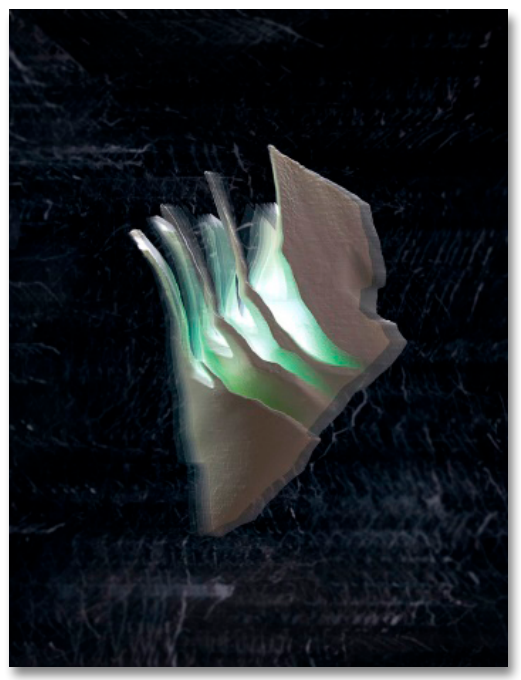

\section{Education and human rights for muslim women}

\section{$\overline{\text { Allana de Freitas Lacerda }}$}

Estudante de doutorado em Human Rights in Contemporary Societies da Universidade de Coimbra. E-mail: allana_lacerda@yahoo.com.br.

\section{Francisca Geny Lustosa}

Professora da linha de História e Educação Comparada do Programa de Pós-Graduação em Educação Brasileira da Universidade Federal do Ceará. E-mail: franciscageny@ yahoo.com.br.
ABSTRACT: The article discusses the right to education for women in Islamic communities and their expression of universality in the human rights' field. The data is the product of a qualitative research (bibliographical, documentary and field), from 2017. The results pointed to the presence of economicpolitical-cultural-religious factors as impediments and/or favoring the right to education, in addition to circumstances of war/endangered territories, socioeconomic condition and/or social/ religious rules still ingrained.

KEYWORDS: Muslim Woman. Discrimination. Human Rights.

$$
\begin{aligned}
& \text { RECEBIDO EM: } 30 / 11 / 2017 \\
& \text { APROVADO EM: } 31 / 12 / 2017
\end{aligned}
$$




\section{INTRODUÇÃO}

Esse artigo tem como objetivo refletir sobre a problemática do direito à educação de mulheres em comunidades muçulmanas, pautado em uma análise de sua expressão de universalidade. Essa análise, por sua vez, está inserida no âmbito dos direitos humanos básicos aos indivíduos, quando em contextos geo-sócio-políticos e culturais tão distintos em suas fundamentações como é o caso das comunidades islâmicas. ${ }^{1}$

Por tal razão, diversas indagações são levantadas sobre a temática: como esse direto é reconhecido nas leis próprias dessa realidade social? Como são considerados fatores como a questão do gênero, a religião, os costumes, ou seja, a cultura islâmica como um todo em seus instrumentos jurídicos? Quais elementos influenciam na consecução dos direitos desses sujeitos dentro da comunidade islâmica? Do ponto de vista dogmático, tem-se espaço para a perspectiva do direito à educação?

Cabe, portanto, compreender como as leis próprias a essas comunidades dispõem a questão. ${ }^{2}$ Além disso, cabe entender essa questão aliada a outras evidências que apontem para o conhecimento sobre os sistemas educacionais islâmicos, bem como sobre os impactos das questões políticas, econômicas, culturais, religiosas e conjunturais em suas ideias e formas de organização, por meio do estabelecimento das relações entre o normatizado nas legislações locais ${ }^{3}$ e internacionais e a voz dos próprios "sujeitos de direito".

A condição do feminino - a princípio, temática já extremamente complexa e tensionada -, nesse caso em particular, é agravada, inclusive, pela circunstância contemporânea que envolve esses grupos sociais (contextos inóspitos de guerra, refugiados,

1 Esse artigo é parte da pesquisa de mestrado realizada na linha História da Educação Comparada do Programa de Pós-Graduação em Educação Brasileira da Universidade Federal do Ceará (UFC), em 2017, sob a orientação da Profa. Dra. Francisca Geny Lustosa. Cf. Lacerda (2017).

2 As comunidades islâmicas analisadas, neste artigo, incluem especialmente Arábia Saudita, Brasil, Faixa de Gaza, Líbano e Paquistão.

3 No caso das comunidades islâmicas, incluem-se o prescrito na Shariah, conjuntos de leis islâmicas que abrangem o Alcorão, a Sunnah, etc. 
proliferação de representações sociais mais imediatas, ligadas ao terrorismo, etc.).

No mundo caótico atual, marcado por um contexto social hegemônico de globalização e de exclusão, assenta-se um cenário envolvendo, por vezes, nações religiosas com posicionamentos conservadores ou, em alguns casos, extremistas. Essas nações estão sujeitas aos ideais de modernidade e têm opiniões díspares em certa medida, que impactam sobremaneira no acesso, reconhecimento e possibilidade de usufruto de alguns direitos, rejeitando, em contraste e/ou oposição às concepções de inter/multiculturalidade, o respeito à dignidade humana e à inclusão - paradigmas contemporâneos das sociedades democráticas.

Interessa, portanto, o Direito, a Educação e notadamente suas relações, uma vez que tal problemática se faz presente em um emaranhado de aspectos sócio-culturais, religiosos, político-econômicos que a integram como um mosaico. Todavia, é a garantia da educação como direito humano, por excelência, que nos mobiliza à defesa.

Em consonância com tais discursos mundiais de direitos, de cidadania planetária, de paz mundial, de emancipação humana (BOBBIO, 2004; LEITE, 2002; NASCIMENTO, 2009; SANTOS, 2009; SEN; KLIKSBERRG, 2010), cabe esclarecer que não é a intenção comparar para hierarquizar ou ranquear sociedades (ou algo dessa natureza), pois, como bem destaca Mahmood (2008), existe a necessidade de não se fazer um julgamento moral e político.

Assim, em contextos específicos que envolvem mulheres, localizadas em situações históricas e culturais particulares, não basta simplesmente ressaltar, por exemplo, que uma tradição de religiosidade ou "modéstia" feminina serve para dar legitimidade à subordinação e à inferioridade das mulheres (DEMANT, 2015). Pelo contrário, seria por meio da análise dessas tradições, em relação aos compromissos práticos e aos modos de vida em que estão inseridas, que poderíamos compreender o significado que a subordinação tem para as mulheres (MAHMOOD, 2008, p. 210).

Nesse sentido, em termos de educação, notadamente, faz-se pertinente uma análise crítica e social-reflexiva (SANTOMÉ, 2013). Essa análise deve, pois, ser elaborada de maneira que busque 
ultrapassar qualquer viés fragmentado, visto que não é oportuno e não tem mais sentido analisar uma realidade com base apenas em um único aspecto, de maneira unidisciplinar.

A possibilidade de se reivindicar direitos ditos universais e inerentes aos sujeitos marca a busca por uma dignidade mínima e a real aplicação e efetivação desses direitos, como o da educação, nos diferentes sistemas e sociedades internacionais, cujos aspectos são relevantes e devem ser destacados.

Cumpre salientar que a questão da universalidade do direito humano é indicada como uma construção ocidental e que pode não representar uma concepção de dignidade humana em outras culturas (SANTOS, 2009). Portanto, a análise da temática do direito à educação, notadamente para mulheres, deve considerar aspectos tais como a emergência de tensões e os conflitos históricos, religiosos e culturais entre as diversas nações do ocidente e do oriente.

Ao que se apresenta não se pode apenas aplicar a noção dos direitos humanos, sem considerar os diferentes fatores (sociais, religiosos, culturais, etc.) que a influenciam. Caso contrário, estaríamos incorrendo numa visão hermética do direito. Nesse sentido, não basta a pura e simples aplicação dogmática do direito, no caso em exame. Cabe o reconhecimento do direito da mulher muçulmana à educação.

Assim, a partir da problemática exposta, envolvendo os sujeitos de direitos islâmicos e a educação, busca-se conhecer como essa relação é expressa na legislação internacional e na vida dos sujeitos destas realidades. Para tanto, o estudo organiza-se sob os seguintes questionamentos orientadores: como o direito à educação é abordado em comunidades islâmicas? Nas legislações, quais são as concepções socioculturais e pedagógicas e as formas de organização dos sistemas de ensino em comunidades islâmicas? Quais as possibilidades e desafios enfrentados por mulheres muçulmanas em relação ao direito de acesso à educação?

Os resultados apresentados nesse artigo são fruto de um estudo qualitativo, realizado no decorrer do ano de 2017, que reuniu informações por meio da coleta de dados teórico-conceituais, da pesquisa bibliográfica (em livros e artigos científicos) e da pesquisa 
documental aliada ao trabalho empírico ${ }^{4}$ que se realizou junto a 11 sujeitos: 5 muçulmanos, nos próprios campos de refugiados (por meio de questionários endereçados via e-mail, em inglês); 4 depoimentos do sítio eletrônico TED.COM; ${ }^{6} 3$ entrevistas a brasileiros revertidos ${ }^{7}$ à religião muçulmana, em dois Centros Islâmicos de Fortaleza. Alguns desses resultados serão apresentados nos próximos tópicos.

\section{O PENSAMENTO CONTEMPORÂNEO DOS DIREITOS HUMANOS E SUA RELAÇÃO COM A MULHER MUÇULMANA - GÊNERO, SEXUALIDADE E RELIGIÃO NA CONCEPÇÃO ISLÂMICA}

Abordam-se, neste tópico, questões acerca da importância e do funcionamento/caracterização da escola e da educação para a mulher, em comunidades islâmicas, e da relação dessa configuração sociocultural e educacional com o pensamento contemporâneo de direitos humanos. O interesse é o de saber se as informações acerca da discriminação de gênero e educação coincidiriam com as realidades e experiências de vida dos sujeitos.

\footnotetext{
4 O trabalho de campo foi realizado junto a 8 mulheres muçulmanas e 3 homens muçulmanos de diferentes nacionalidades, condições sociais, locais de moradia e profissões, o que permitiu coletar e apresentar ao leitor uma rica variedade de percepções sobre o tema da pesquisa.

5 Os sujeitos com nomes fictícios são: Indira (paquistanesa que mora na Noruega), Salomão (palestino que mora no Líbano), Benazir (palestina que mora na Faixa de Gaza), Khadija (saudita que mora na Arábia Saudita); Sherazade (brasileira revertida), Mordecai e Ester (casal de brasileiros revertidos). Os depoimentos coletados no site TED são de: Mustafa Akyol (turco), Dalia Mogahed (egípcia que mora nos EUA), Yassmin Abdel-Magied (Sudanesa que mora na Austrália) e Alaa Murabit (libanesa).

6 O TED é um site de divulgação de ideias, por meio de conversas/depoimentos de grande impacto, dedicando-se aos mais variados assuntos e temas políticos, econômicos, religiosos e culturais. A seleção dos depoimentos foi realizada com os termo-descritores "muslim" e "muslim woman". Mais informações sobre essa organização podem sem acessadas no site: <https://www.ted.com/ about/our-organization>.

7 Do ponto de vista do Islã religião, não há diferença entre muçulmanos ou aqueles que se "revertem" ao Islamismo. O termo utilizado é "reversão" e não "conversão", uma vez que para os indivíduos muçulmanos, uma pessoa não se converte para a religião, mas sim no sentido de que os indivíduos em questão sempre foram muçulmanos e, por algum motivo (de nascimento, de origem), "desviaram-se" da religião e agora estão retornando.
} 
Procurando conhecer mais sobre os aspectos determinantes no direito à educação para mulheres, indagou-se aos sujeitos sobre a dinâmica do funcionamento da educação escolar de mulheres em comunidades islâmicas, por exemplo, se haveria igualdade de acesso a materiais didáticos e aulas, se haveria separação por gênero no espaço físico ou ainda se haveria algum tipo de discriminação e de que tipo.

Yousafzai e Lamb (2013) apontam a existência de discriminação por gênero e as políticas adotadas pelo Talibã, em particular, apresentando aspectos que influenciavam na não consecução do direito à educação para as mulheres e meninas de seu país, frente ao conflito armado recente. Também afirmam sua resistência à negação desses direitos sob justificativas em preceitos religiosos ligados ao Islã: "Era como muçulmana que eu defendia meu direito de ir à escola". (YOUSAFZAI; LAMB, 2013, p. 296).

Malala prossegue seu relato escrito, mostrando o fosso ainda existente quanto ao reconhecimento do direito à educação, diante de indicadores quantitativos de seu país em termos de analfabetismo de mulheres e de crianças fora da escola, mesmo que a constituição já incorpore a educação como direito de todos. Sua fala denuncia:

[...] Hoje todos sabemos que a educação é nosso direito básico. E não só no Ocidente; o Islã também nos deu esse direito. [...] No Corão está escrito que Deus quer que tenhamos conhecimento .[...] A luta é grande. No mundo existem 57 milhões de crianças fora da escola primária. Delas, 32 milhões são meninas. É triste, mas meu país, o Paquistão, ocupa um dos piores lugares: 5,1 milhões de crianças não vão sequer à escola primária, mesmo que na nossa Constituição esteja escrito que toda criança tem esse direito. Há quase 50 milhões de adultos analfabetos, dois terços mulheres - como a minha própria mãe. (YOUSAFZAI; LAMB, 2013, p. 326).

O trecho expõe o panorama desse país e seus indicadores educacionais, cujo interesse político é ser mantido dessa forma. Mostra também que, para Malala, não se trata do texto do Alcorão, muito menos uma questão de não figuração jurídica ou nas leis, 
pois existe previsão legal garantindo o direito à educação. Nessa circunstância, o que provoca, então, esse grande número de mulheres muçulmanas analfabetas, de mulheres que não têm direito à educação ou de mulheres que possuem acesso restrito?

No caso da Malala, no Paquistão, tem-se uma questão tanto religiosa, como política e de gênero. A questão é política, porque, quando o Talibã assumiu o controle daquela região, impôs seus ideais e suas regras restritivas, sendo a maioria delas uma postura religiosa considerada como ultraconservadora, principalmente quanto a como figurava a mulher na sociedade, e a educação tomada como ideia ocidental.

A questão educacional e a questão de gênero não foram justificativas usadas pelo Talibã como o motivo que levou ao ataque. No entanto, fora exposto não só o posicionamento do Talibã sobre a mulher, sua educação e o "receio" da difusão de ideias que podem gerar renovação e/ou questionamentos contra o sistema político e o modelo repressor estabelecido como foram feitos duros ataques sobre qualquer situação, pessoas ou grupos que se levantem contra o sistema estabelecido e seus interesses. Nesse caso, não é de se admirar a educação ser alvo a atingir, pois ela se faz em arma perigosa nesse sentido.

Excetuando o Paquistão, sob o domínio das forças Talibã, no cenário relatado por Malala, outra indagação também se faz pertinente: como se apresenta a questão educacional para as mulheres nas demais comunidades islâmicas? Os interlocutores dessa pesquisa afirmaram, em todas as suas narrativas, que não existe uma discriminação por gênero para a educação, ou seja, que homens e mulheres são incentivados à educação. Diante dessas respostas, parece que o que se faz necessário entender, de fato, é: por que os interlocutores sugerem que não existe uma discriminação de gênero no que se refere ao incentivo e acesso à educação?

É nesse sentido que Indira faz uma descrição da situação dos países islâmicos em função de seus referenciais de sistemas político-religiosos:

[...] uma verdadeira sociedade muçulmana seria, tecnicamente, apenas a Arábia Saudita, uma vez que as outras sociedades são mais mistas e liberalizadas. O Paquistão é uma 
mistura de cultura que adotou da Índia quando fazia parte do subcontinente indiano. A Indonésia, embora também islâmica, é uma sociedade muito diferente. Uma verdadeira sociedade muçulmana, como a Arábia Saudita, não tem problemas para educar mulheres e meninas. Toda garota tem direito a um lugar na escola/faculdade/universidade. E no próprio Islã, é a maior responsabilidade de um pai assegurar que seus filhos (não importando o gênero) sejam educados. É por isso que é muito claro - o extremismo, uma raiz do analfabetismo entre as mulheres, surge a partir da pobreza em vez de seguir a palavra do islam. Uma sociedade muçulmana, conforme o Islã, não pode restringir a educação de qualquer tipo, uma vez que a religião basicamente diz que você aprenda e explore tudo o que achar curioso. (Indira, 16/05/2017).

Percebe-se que os problemas internos aos sistemas de alguns países refletem na consecução dos direitos em seus territórios. Identifica-se também um círculo vicioso do extremismo à ignorância e à pobreza, reciprocamente. Muito embora, na fala de todos os interlocutores acessados, o Islã é desculpabilizado e justificado no fato de que não prevê tal discriminação em seus preceitos.

Sherazade destaca a fundamental importância da educação e do conhecimento para qualquer sociedade, pois, "só assim ela poderá se proteger do machismo, defender-se, independente de uma nação adotar ou não o islamismo, a mulher deve buscar o conhecimento, a educação" (Sherazade, 25/05/2017). Apesar da defesa da educação da mulher ser usada como instrumento contra posições masculinas mais conservadoras, o discurso da brasileira revertida, escolarizada e com profissão que lhe provê independência financeira não é algo que se aplique aos casos conhecidos das complexas e perversas realidades vivenciadas por mulheres mulçumanas, inclusive daquelas referentes aos contextos que esse estudo também acessou na literatura, assim como no levantamento de matérias jornalísticas e demais produções.

Diferentemente de Sherazade, Ester - também brasileira, casada e responsável materna pela educação dos filhos, no ambiente familiar, ensinando os valores e os costumes islâmicos - afirma 
que, nas escolas de sua religião: "Além das disciplinas comuns é ensinado a purificação, as boas maneiras e tudo que faz parte da nossa religião, da melhor maneira possível" (Ester, 31/05/2017). Ao adotar esse tipo de postura como mãe, definidora do tipo de escola e de educação de seus filhos, afirma que prestigia os aspectos tradicionais e os valores do Islã, não permitindo o contato, a socialização e o acesso a ambientes culturalmente distintos do dela.

Khadija, por seu turno, destaca a participação do governo da Arábia Saudita no estímulo à educação; contudo, ressalta alguns aspectos que identificam uma divisão de gênero, circunstância essa refletida inclusive na interferência das vestimentas femininas: "Normalmente, o governo constrói uma escola. Em algumas áreas remotas, o governo aluga casas. Mas meninas ficam na sua classe [...]. As meninas usam uniformes, e as professoras usam saias" (Khadija, 21/05/2017).

É evidente na fala da Khadija a existência da divisão por gênero, quando aponta que as meninas ficam em salas específicas e que mulheres usam trajes específicos. A questão da vestimenta, consequentemente, a figura do véu islâmico são pontos atualmente polêmicos/controversos no Islamismo, principalmente em países mais conservadores, como é o caso da Arábia Saudita.

A diferenciação de tratamento em virtude de gênero é destacada por Khadija, ao caracterizar como é a educação para mulheres e meninas na Arábia Saudita. Ela afirma que essa distinção é encontrada, inclusive, quanto às matérias estudadas em sala de aula, tendo as meninas aulas relacionadas a assuntos do lar e práticas domésticas e os meninos, a áreas como a educação física:

É definitivamente orientado para o gênero, me ensinaram a tirar manchas difíceis de roupas e pisos quando eu estava no $8^{\circ}$ ano eu acredito, quando cheguei em casa e perguntei ao meu irmão mais velho ( 4 anos mais velho) se ele foi ensinado o mesmo, ele disse que ele tinha educação física em vez disso, o que não temos. Embora os meninos também não tenham uma opção de economia doméstica. Eu sei que agora em escolas privadas, a educação das meninas é muito mais avançada, não sei se eles realmente ensinam o mesmo 
que os meninos (duvido muito disso, mas eles tentam interessá-las em campos orientados para homens tanto quanto seja realisticamente possível). (Khadija, 21/05/2017).

A Arábia Saudita é apontada nas falas dela como tendo uma visível discriminação por gênero, fundamentada em preceitos religiosos islâmicos. Todavia, também é usada como exemplo por Mordecai e Ester como uma nação que tem a presença da maior universidade para mulheres do mundo, a Princess Nora University, em Riade. Apesar de os informantes não perceberem dessa forma, o fato denota, por esse mesmo motivo, a marca da separação de gênero para a educação. Não é à toa se tem uma universidade para mulheres.

A Arábia Saudita figurou nos discursos obtidos como sendo um país mais conservador na questão tematizada por esse estudo e como tendo poucos avanços na questão da igualdade de gênero, muito embora tenha adotado os instrumentos legais que normatizam os direitos humanos islâmicos, quais sejam a Declaração Islâmica Universal dos Direitos Humanos (1981), ${ }^{8}$ a Declaração do Cairo sobre Direitos Humanos Islâmicos (1990) ${ }^{9}$ e a Carta Árabe de Direitos Humanos (2004). ${ }^{10} \mathrm{O}$ fato de existir discriminação de gênero quanto à vestimenta da mulher e às matérias ministradas nas escolas, portanto, contraria diretamente os documentos de direitos humanos islâmicos supramencionados. Questões políticas e religiosas que marcam o conservadorismo, como na Arábia Saudita, podem acarretar as diferenças de tratamento e de acesso à educação.

Apesar dos relatos que fazem a configuração de que existe distinção do direito e do tipo de educação para as mulheres, desde a diferença de utilização dos materiais didáticos até as matérias curriculares ministradas, a maioria dos sujeitos se posicionou como não sendo "favorável à distinção em razão do gênero". Alguns, como Indira, até ressaltaram que "ambos devem ir à

8 Para mais informações, cf. Declaração Islâmica... (1981).

9 Para mais informações, cf. Declaração... (1990).

10 Para mais informações, cf; Carta... (2004). 
escola, estudar os mesmos assuntos, aprender com os mesmos livros" (Indira, 16/05/2017).

Indira também relata que a maioria das carreiras ditas masculinas tem o maior número de mulheres, como se percebe neste trecho de sua declaração: "Você ficaria surpreso ao saber que as melhores escolas de negócios, médicos e de engenharia em todo o Paquistão têm o maior número de estudantes mulheres do que homens!" (Indira, 16/05/2017). Ela ressalta ainda a grande participação feminina na educação e no mercado de trabalho:

Assim, como mencionado anteriormente, se esta entrevista é baseada apenas em minhas experiências de vida, não vi diferença entre uma escola americana versus uma escola paquistanesa. Minha escola tinha pelo menos $50 \%$ de estudantes do sexo feminino na minha turma. Minha escola de negócios tinha cerca de 60\%. Quando eu trabalhava no Paquistão, pelo menos $40 \%$ da força de trabalho da organização também era do sexo feminino. Então, para mim, é absolutamente normal que qualquer um e todos se eduquem. (Indira, 16/05/2017).

Indira, no entanto, evidencia alguns aspectos que são responsáveis pela separação física e intelectual da educação em virtude do gênero, quando ocorre, atribuindo à presença de extremismos de fatores culturais e religiosos. Tomando como exemplo o Paquistão, nossa interlocutora declarou que a separação de classes/escolas para meninos e meninas só ocorre até chegar o ensino médio, nas cidades, quando o sistema passa a ser misto ( $\mathrm{Co}-\mathrm{ed}$ ), excetuando casos em que famílias consideradas mais extremistas do ponto de vista religioso preferem o ensino em escolas sectarizadas por gênero, ainda mantido como opção:

Na maioria das grandes cidades, a educação é co-ed, o que significa que meninos e meninas estudam nas mesmas salas de aula (no mesmo tempo e lugar). Não há absolutamente nenhuma divisão no espaço dentro da escola. O material de ensino também é o mesmo. Mas, existem escolas especializadas somente para meninas ou meninos que foram criadas para as pessoas que pensam mais extremamente na sociedade e que não querem que 
as meninas estudem com os meninos. Isso, entretanto, só pode ser seguido até o ensino médio porque todas as faculdades e universidades no Paquistão são co-ed. Portanto, há muito incentivo para a educação universal para ambos os sexos em cidades médias e grandes, a fim de prepará-los para o ensino universitário, onde eles vão interagir com sexos opostos. (Indira, 16/05/2017).

No entanto, ela salienta não ser essa a realidade das aldeias. Por exemplo, no Paquistão, não há estimulo à educação: ocorre a preferência ao trabalho no campo, às atividades econômicas realizadas pelas famílias, à preservação da descendência e do casamento, dentre outros aspectos culturais e religiosos. O aspecto cultural-religioso, com assento nas aldeias, prevalece como definidor:

O pessoal do campo também tende a ter uma atitude mais extrema no que diz respeito ao Islã, por isso é possível que, mesmo se eles eduquem os filhos, serão os meninos e não as meninas. Isso também é devido a um medo de que se as meninas são educadas, então potenciais maridos com baixa educação e boa família não vão querer casar com elas. Os homens nessas áreas também temem que, se as mulheres se formem, nunca mais querem viver com homens tão atrasados e, portanto, irão migrar para cidades maiores. (Indira, 16/05/2017).

Um dos entrevistados, Salomão, frisa que apenas uma pequena porcentagem da população não reconhece a educação para mulheres como importante, nos dias de hoje, mas também aponta a existência de escolas para homens e mulheres, assim como de escolas mistas. Dependendo da instituição escolar, podem-se ter, por exemplo, somente mulheres lecionando; em outras escolas, há professores de ambos os sexos. Assim, ele explica que:

A educação básica em sociedades muçulmanas é muito importante tanto para homens quanto para mulheres. Algumas vezes você ouve dizer que não é importante para as mulheres, mas essas pessoas representam nem 10\% dos muçulmanos. Nós temos escolas misturadas (meninos e meninas), como 
também só para homens e só para mulheres. (Salomão, 12/12/2015).

A questão da educação quando em áreas de campos de refugiados deve ser considerada na análise desse panorama de comunidades muçulmanas. Há entre os entrevistados Benazir, residente na Faixa de Gaza e que ressalta que não há uma divisão por gênero do material didático, das matérias a serem ministradas, do espaço físico nem da convivência entre mulheres e homens. Essa não diferenciação se estende também a seus professores e professoras. Assim, comunica:

Até o término da $4^{a}$ Série das escolas primárias meninos e meninas assistem aulas no mesmo local e horário. Não há uma divisão de espaço dentro da própria escola. O material didático e as aulas ministradas são as mesmas. Não há diferenciação de gênero quanto aos professores, mas a maioria são mulheres na educação primária. Há muitas escolas para refugiados da UNRWA e, caso os alunos queiram, eles podem estudar nas escolas do Governo. Isso depende das preferências dos pais. (Benazir, 14/01/2016).

Devem-se realçar dois pontos que surgem na fala da Benazir. O primeiro ponto é que se tem uma feminilização da docência, ou seja, ainda é uma carreira predominantemente ocupada por mulheres. O outro ponto é a configuração dos pais como figuras de decisão no tipo de educação dos filhos, em que eles podem optar ou por um sistema de ensino com outros referenciais ou por modelos tradicionais cuja única variante é a sexista, para o espaço escolar.

Pelas falas apresentadas, percebem-se distinções e variações quanto às formas de usufruto da educação para as comunidades islâmicas à mercê de muitos fatores, circunstâncias, especificidades e particularidades que marcam sua possibilidade de ocorrência. Como afirma Tohidi (2008), a religião seria apenas um dos fatores determinantes, entre muitos outros, do status e dos direitos-usufruto das mulheres, sendo sua influência mediada por fatores sócio-econômicos, bem como por políticas estaduais, sistema educacional e outras instituições socioculturais. 


\section{PERCEPÇÕES DOS SUJEITOS SOBRE AS RELAÇÕES DE GÊNERO, TRABALHO E CASAMENTO}

Nesse tópico, será abordada a possibilidade de conciliação entre ser uma mulher muçulmana, mãe e profissional qualificada num mercado masculino muito competitivo, na perspectiva do Islã e nos discursos dos sujeitos. A realidade apresentada nas falas dos entrevistados leva em consideração aspectos, como família/casamento x trabalho/educação. Eles apontam para um avanço, um início de uma inclusão de gênero, embora ainda persistam aspectos limitadores e discriminadores.

No que concerne ao acesso ao ensino superior e à qualificação profissional, alguns sujeitos apontam a questão acadêmica e político-institucional como fatores a serem analisados. Dessa maneira, com relação à questão acadêmica, os sujeitos destacaram que os estudantes devem tirar boas notas para poderem cursar faculdades ou universidades e escolherem seus cursos, independentemente se são homens ou mulheres. Em outras palavras, isso sugere não haver restrição de gênero quanto à escolha da carreira.

Por outro lado, o que pode ocorrer são diferenciações de gênero a atender, em virtude da política interna das próprias instituições de ensino superior: existem universidades mistas ou só para mulheres. No entanto, existe um critério avaliativo de notas e rendimento acadêmico também determinante:

Depende da própria faculdade, se a mesma é só para mulheres ou elas podem assistir junto com outros homens. Algumas universidades ensinam para homens e mulheres ao mesmo tempo; outras separam pelo gênero. A dinâmica do funcionamento das aulas e do fato de as mulheres e homens frequentarem as aulas na mesma sala e no mesmo horário vai variar de acordo com as regras da Universidade. O número de mulheres nas faculdades é alto, mais alto do que o número de homens. Há muito interesse por parte das mulheres. Não existe limitação de escolha dos cursos, vai de acordo com suas notas durante a escola secundária. (Benazir, 14/01/2016). 
As mulheres que conseguem ter acesso à universidade superam todas as barreiras e obstáculos, ainda que separadas pelo gênero. Nas grandes e médias cidades, há uma elevação nos indicadores de formação superior das mulheres:

As aulas são dadas como elas são normalmente ensinadas em qualquer instituição de ensino em todo o mundo. Docente entra, oferece uma palestra, faz perguntas, demonstra experiências práticas e os alunos tomam notas. Essa didática é obviamente a mesma para homens e mulheres, que ambos frequentam a classe na mesma sala e, ao mesmo tempo. O número de mulheres nas faculdades é extremamente elevado em média, cidades grandes ou médias, com mulheres se destacando na maioria das posições elevadas, acadêmicas inclusive. Em aldeias ou cidades menores, o número é comparativamente muito menor. Em geral, há muito interesse em mulheres para estudar mesmo que elas não desejem continuar em uma esfera profissional. (Benazir, 14/01/2016).

Cumpre destacar que essa informação proporciona a percepção de avanços na busca pela igualdade de oportunidades e de tratamento, compreensão que pode se reverter em avanços na discussão, na ampliação dos debates e nas rupturas da condição de mulheres e meninas a quem se nega ou restringe a educação e que sofrem violência e violação de seus direitos sociais e educacionais. A partir da formação de uma geração de mulheres com elevado nível de instrução escolar, que teve direito ao acesso à educação, podem-se ter repercussões na educação de base das próximas gerações femininas.

Outro elemento apontado é o de cada vez mais as mulheres conseguirem se inserir no mundo do trabalho, via frequência no ensino superior, com a garantia de se profissionalizarem, inclusive, em carreiras antes consideradas como masculinas. A fala de Indira confirma isso:

Geralmente as mulheres optam por estudar negócios, artes e literatura e medicina. Eu acredito que a medicina é o mais popular para as mulheres e é visto como uma profissão 
muito feminina no Paquistão. Há poucas mulheres nas áreas de engenharia e matemática e áreas afins. (Indira, 16/05/2017).

Algumas carreiras são reconhecidas como as mais procuradas por mulheres, como a medicina, caso que pode ser provavelmente justificado pela obrigatoriedade das mulheres muçulmanas de serem atendidas por médicas. A situação aqui vislumbrada é: como ter médicas formadas em um país que impede, cerceia e/ou limita a educação, diferenciando-a para suas meninas e mulheres?

Outras carreiras aparecem como sendo subvalorizadas, como a de professora:

Ensinar no Paquistão é tido mais como uma profissão feminina que não paga muito e é melhor para as mulheres casadas que desejam ter uma vida profissional mais fácil. Assim, a maioria é do sexo feminino, com exceção de professores de ginástica ou às vezes professores de matemática ou física que são do sexo masculino. (Indira, 16/05/2017).

Outra variável que emergiu das respostas dos sujeitos se refere ao grau de interesse das mulheres em exercer profissionalmente suas carreiras ou não. Em outras palavras, se há apenas interesse pela diplomação, por exemplo. As respostas fornecidas se apresentaram bastante divididas. Benazir afirmou que as mulheres têm interesse no exercício da profissão: "Elas costumam exercer suas profissões, não querem apenas o diploma. Se elas puderem conseguir alguma posição profissional, elas praticariam suas profissões" (Benazir, 14/01/2016).

Indira afirma que as mulheres costumam buscar somente o diploma, optando pelo casamento e cuidado da casa: "A maioria das mulheres só deseja um diploma universitário não uma profissão. Na minha cidade (Karachi), quase 50\% continuam em rumo a uma carreira profissional enquanto que outras simplesmente se casam e se tornam donas de casa" (Indira, 16/05/2017). Cumpre destacar que ela destaca a importância da educação para além da profissionalização:

Nestes tempos de alta inflação, especialmente, é mais difícil confiar em um homem como único gerador de pão da família. Uma mulher 
educada pode ajudar compartilhando responsabilidades. Mesmo que a mulher planeje não trabalhar depois do casamento ou pós-filhos, a educação ajuda as mulheres a se tornarem melhores mães que estão mais conscientes dos arredores, da sociedade, do que se encaixa melhor com a educação da criança, a saúde etc. (Indira, 16/05/2017).

Quanto à previsão e garantia legal do direito ao trabalho e não discriminação, documentos legais referendam igualdade de tratamento e de oportunidades, como as disposições da Declaração Universal dos Direitos Humanos, da Declaração do Cairo sobre Direitos Humanos Islâmicos, da Carta Árabe dos Direitos Humanos e da Declaração Islâmica Universal dos Direitos Humanos.

Foi consenso de que há mais oportunidades para os homens, muito embora a figura feminina esteja crescendo no mercado de trabalho e tenha conquistado posições destinadas à figura masculina:

Não há absolutamente nenhuma discriminação de gênero no local de trabalho. O Paquistão é o único país muçulmano a ter tido um chefe de Estado e os poucos países que tiveram um chefe de Estado (eu acredito EUA ainda está esperando pela deles), bem como as mulheres chefes de organizações, oradoras do parlamento, etc. A relação de trabalho é boa entre homens e mulheres. Não há problemas com relação a tal situação. Hoje em dia, as mulheres estão cada vez mais assumindo papéis que elas não eram esperadas liderar talvez algumas décadas atrás. (Indira, 16/05/2017).

Também ligadas à educação como desdobramento, as relações com o mundo do trabalho e a profissionalização inspiram indagações: qual seria o posicionamento acerca de uma mulher ter um trabalho e contribuir financeiramente nas despesas da casa? Qual o impacto na dinâmica familiar se a mulher for também uma provedora do lar? Nesse sentido, interessaram também as distintas acepções jurídicas na relação entre o casamento e a dinâmica familiar, bem como a noção de divisão dos papéis dentro da família, a fim de vislumbrar o impacto e/ou relações com a educação. 
A obrigação de priorizar a família e se dedicar aos filhos e ao marido, em detrimento do investimento numa carreira profissional ou, até mesmo, do direito de escolher com quem vai se casar, foram fatores de interferência na educação.

A questão é posta da seguinte forma, nas disposições jurídicas estudadas nessa investigação: na Declaração Universal dos Direitos Humanos (1948), há a previsão de igualdade entre homens e mulheres no que se refere aos direitos e às obrigações no casamento:

Art. $6^{\circ}$ :

1. A partir da idade núbil, o homem e a mulher têm o direito de casar e de constituir família, sem restrição alguma de raça, nacionalidade ou religião. Durante o casamento e na altura da sua dissolução, ambos têm direitos iguais.

2. O casamento não pode ser celebrado sem o livre e pleno consentimento dos futuros esposos.

3. A família é o elemento natural e fundamental da sociedade e tem direito à proteção desta e do Estado. (ONU, 1948).

Na Declaração do Cairo sobre Direitos Humanos Islâmicos (1990), a constituição da família por meio do casamento é vista como o fundamento da comunidade islâmica, tendo os homens e mulheres equivalência de direitos:

Art. $5^{\circ}$ :

a) A família é o fundamento da sociedade, e o casamento é a base de uma família. Os homens e as mulheres têm o direito ao casamento, e sem as restrições decorrentes de raça, cor ou nacionalidade deve impedir-lhes de exercerem esse direito.

$[\ldots]$

Art. $6^{\circ}$ :

a) A mulher é igual ao homem em dignidade de pessoa humana, tem o seu próprio direito de desfrutar, bem como as funções a executar, como também possuir a sua própria 
identidade civil e independência financeira, ainda o direito de manter seu nome de linhagem.

\section{b) O marido é responsável para a ma- nutenção e bem-estar da família. (DECLARAÇÃO..., 1990 - grifo nosso).}

A determinação de que o marido é o responsável pela manutenção da família pode ser uma das justificativas utilizadas, para a mulher ter que sair do trabalho e cuidar da casa e dos filhos. Essa contradição entre igualdade de direitos e o reconhecimento do homem como aquele que vai sustentar a família é verificada na fala dos sujeitos entrevistados, por exemplo, quando Salomão se manifesta pelo crescimento da figura feminina no mercado de trabalho e, em contrapartida, declara que sua esposa sairá do emprego para cuidar da casa e dos filhos, em uma decisão em conjunto com a sua esposa: "minha esposa é professora e minha irmã é gerente de Recursos Humanos. Nos próximos anos, provavelmente a minha esposa sairá da escola em que trabalha para cuidar dos nossos filhos, mas isso é algo que podemos decidir juntos depois" (Salomão, 12/12/2015).

Essa noção também é apresentada na Declaração Islâmica Universal dos Direitos Humanos (1981), em que o direito de casar e constituir família é algo a ser buscado, tendo a mulher e o homem obrigações e responsabilidades de acordo com seu sexo e suas inclinações naturais:

XIX - Direito de Constituir Família e Assuntos Correlatos

a. Toda pessoa tem o direito de se casar, constituir família e ter filhos, de acordo com sua religião, tradições e cultura. Todo cônjuge está autorizado a usufruir tais direitos e privilégios e deve cumprir essas obrigações na conformidade do estabelecido na Lei.

b. Cada um dos parceiros no casamento tem direito ao respeito e consideração por parte do outro.

c. Todo marido é obrigado a manter sua esposa e filhos, de acordo com suas possibilidades. 
h. Na família, homens e mulheres devem compartilhar suas obrigações e responsabilidades, de acordo com o sexo, dotes naturais, talentos e inclinações, sem perder de vista as responsabilidades comuns para com os filhos e parentes.

[...]

XX - Direitos das Mulheres Casadas

Toda mulher casada tem direito a:

a. morar na casa em que seu marido mora;

b. receber os meios necessários para a manutenção de um padrão de vida que não seja inferior ao de seu marido e, em caso de divórcio, receber, durante o período legal de espera (iddah), os meios de subsistência compativeis com os recursos do marido, para si e para os filhos que amamenta ou que cuida, independente de sua própria condição financeira, ganhos ou propriedades que possua; [...] (grifo nosso) (DECLARAÇÃO ISLÂMICA..., 1981 - grifo nosso).

A disposição no inciso XX, alínea b ratifica a fala de Indira, ao declarar que a figura do homem/esposo e seu pensamento conservador acabam por prejudicar a profissionalização e o exercício do trabalho pela mulher:

Geralmente não há resistência por parte dos pais ou do ambiente externo na busca ou exercício de uma profissão, se você tem um diploma universitário. Pode, contudo, ter alguma resistência do marido em termos de quem está ganhando mais. Homens no Paquistão tendem a ter um grande ego. E, embora a maioria dos homens perceba a importância de ter sua esposa trabalhando para proporcionar uma vida melhor para a família, há argumentos e dissensões quando as mulheres ganham mais, simplesmente porque vai ferir o ego do homem. As mulheres não são os ganhadores de pão clássico (exceto para as mães solteiras, por exemplo), mas a sua ajuda no fornecimento para a casa é quase sempre bem vinda. (Indira, 16/05/2017). 
Na Carta Árabe dos Direitos Humanos (2004), a importância da família é destacada, devendo sua proteção ser assegurada pelo Estado e pela sociedade:

Art. $11^{\circ}$ :

Todas as pessoas são iguais perante a lei e têm o direito de desfrutar da sua proteção, sem discriminação.

[...]

Art. $33^{\circ}$ :

1. A família é o núcleo natural e fundamental da sociedade; ela é baseada no casamento entre um homem e uma mulher. Os homens e as mulheres com idade para casarem-se têm o direito de formar uma família, segundo as regras e condições do casamento. O casamento não pode acontecer sem o pleno e livre consentimento de ambas as partes. A legislação em vigor regula os direitos e deveres do homem e da mulher quanto ao casamento, durante o casamento e na sua dissolução.

2. O Estado e a sociedade devem assegurar: a proteção da família, o fortalecimento dos laços familiares, a proteção de seus membros e a proibição de todas as formas de violência ou de abuso nas relações, em especial contra mulheres e crianças. [...] (CARTA..., 2004).

Nas legislações supramencionadas, figura a noção de independência financeira tanto para o homem quanto para a mulher e, excetuando a Declaração Universal dos Direitos Humanos, todas afirmam a obrigatoriedade do homem como provedor do lar. Depreende-se, então, que a mulher pode trabalhar e que pode contribuir financeiramente nas despesas da casa, mas isso é relativizado a questões que se ligam ao masculino (pais/casamento/marido).

Alguns sujeitos declararam, ainda, que as mulheres podem ser requisitadas a trabalhar, por conta de fatores econômicos. A questão de necessidade financeira e de que as mulheres trabalhem, então, pode ser vista nos campos de refugiados, como a Faixa de Gaza:

Não há resistência no âmbito da sua própria família e no ambiente externo, pois a maioria das mulheres bem sucedidas são mais requisitadas para trabalhar. Ressalta-se, contudo, 
não que as mulheres que trabalham são mais sortudas em se casarem do que aquelas que não trabalham, porque na Faixa de Gaza nós temos um alto custo de vida e um salário só não é suficiente. (Benazir, 14/01/2016).

Cumpre mencionar que o entendimento acerca da independência financeira e do direito ao trabalho da mulher, previstos e garantidos pelos instrumentos jurídicos, são postos em negação diante de alguns posicionamentos conservadores dos países islâmicos e de relatos que foram coletados sobre o acesso à educação.

Registra-se ainda que a negociação da Convenção sobre a Eliminação de Todas as Formas de Discriminação contra a Mulher (ONU, 1979), apesar de esse documento ter tido ampla adesão dos países, foi a que mais apresentou reservas nos seus dispositivos, principalmente na cláusula relativa à igualdade entre homens e mulheres no âmbito familiar, ou seja, em relação ao lugar dicotômico da mulher nos espaços público e privado (PIOVESAN, 2008). As nações que mais apresentaram reservas nessa convenção são países de maioria islâmica (IBRAHIM, 2011) e os artigos que mais sofreram reservas ${ }^{11}$ foram por conflitarem com a lei da Shariah e da Sunnah. ${ }^{12}$

Assim, embora haja previsão legal expressa para se buscar a isonomia entre os sexos, percebe-se a utilização de justificativas religiosas pelas nações islâmicas ainda que no âmbito das Nações Unidas, para rejeitarem mecanismos igualitários, como o Alcorão Sagrado e seus fundamentos, bem como legislações, quando aplicam a Shariah Islâmica.

Pela análise dos trechos dos depoimentos apresentados, concorda-se com o entendimento de Tohidi (2008, p, 253), quando afirma que: "Historicamente, é a interação entre vários fatores como a geopolítica e o desenvolvimento socioeconômico,

11 Para aprofundamento dessa questão, assinalamos que os artigos que mais sofreram reservas são: artigo 2, alíneas f e g; artigo 9, parágrafos 1 e 2; artigo 15, parágrafo 4; artigo 16, parágrafo 1, alíneas a, c, d, f, g; artigo 29, parágrafos 1 e 2 por tratarem sobre a "igualdade de gênero no âmbito civil, administrativo, político e legislativo, bem como adoção de políticas públicas para combater a discriminação sofrida pelas mulheres".

12 Cf. UN (1979). 
o colonialismo e as políticas estaduais e outros fatores como a cultura patriarcal e a religião ou costumes e tradições locais que moldaram a posição das mulheres em cada país", e consequentemente, a maneira como acedem aos direitos.

\section{CONSIDERAÇÕES FINAIS}

A pesquisa realizada evidencia que existem instrumentos jurídicos específicos sobre direitos humanos islâmicos e suas garantias, como a Declaração Islâmica Universal dos Direitos Humanos (1981), a Declaração do Cairo sobre Direitos Humanos Islâmicos (1990) e a Carta Árabe de Direitos Humanos (2004).

Quanto à questão do direito à educação, destacamos a injunção de múltiplos fatores (econômicos, sociais, geográficos, culturais, políticos e religiosos) que influenciam no acesso, na consecução e na dinâmica de ensino ofertada a homens e mulheres. Depreende-se que a questão de gênero emerge como uma consequência do limite posto às mulheres, porque não se limita a educação aos homens, apenas às mulheres. Quando é o regime político que limita esse direito, é para as mulheres que o fazem: se, em nome da religião, isso for negado (ainda que as escrituras não o façam como defendem alguns sujeitos), são das mulheres que se retira esse direito; se é a questão econômica familiar e/ou a atividade de base das comunidades o motivo justificado, é a mulher que é cerceada desse usufruto.

Apesar de existir situações que comprovam a negação, limitação e/ou cerceamento da educação da mulher, o discurso de defesa desse direito é usado como instrumento contra posições masculinas mais conservadoras. Ainda assim, podem permanecer casos em que complexas e perversas realidades sejam vivenciadas, nos contextos que esse estudo acessou, na literatura e em matérias jornalísticas.

As narrativas de alguns sujeitos desse estudo (com base em suas experiências de vida e no contexto atual) apresentaram a ocorrência de mudanças ao longo dos tempos, muito embora essas mudanças não sejam capazes de se constituir em rupturas na ordem estabelecida ou causar repercussões significativas para 
transformar a ordem historicamente estabelecida quanto à diferenciação entre os gêneros. Tal evidência aponta para uma manutenção desse modelo de desigualdade de gênero por mais tempo ainda, muito provavelmente.

No geral, no que se refere aos valores religiosos do Islã (Alcorão), as referências feitas pelos sujeitos não os apresentam como fator limitador ou restritivo. Pelo contrário, para todos os entrevistados, a busca pelo conhecimento é algo incentivado pelo texto sagrado para homens e mulheres. O problema é a existência de questões econômico-financeiras, sociais e políticas que delineiam também o aspecto cultural e religioso. Essas questões são variáveis no "jogo" e levam à limitação ou à exclusão da execução e aplicabilidade desse direito.

Cumpre mencionar que questões políticas e religiosas com marcas de conservadorismo, como na Arábia Saudita, podem acarretar em diferenças de tratamento e de consecução do direito à educação das mulheres. Todavia, a existência de diferenciação quanto à vestimenta da mulher e às matérias a elas ministradas nas escolas contraria diretamente os documentos de direitos humanos aqui mencionados.

Por fim, salienta-se ainda que a noção de direitos humanos e igualdade entre os gêneros ainda não foi alcançada. Embora tenham havido algumas conquistas jurídicas, sociais e políticas nessa esfera, muitos desafios ainda são postos às mulheres muçulmanas, seja no que concerne ao seu direito à educação ou a qualquer direito humano. 


\section{REFERÊNCIAS}

O ALCORÃO Sagrado. Tradução de Samir El Hayek. Disponível em: <http://www.ebooksbrasil.org/adobeebook/alcorao.pdf >. Acesso em: 28 mar. 2017.

BOBBIO, N. A Era dos Direitos. Tradução de Carlos Nelson Coutinho. Apresentação de Celso Lafer. Rio de Janeiro: Elsevier, 2004.

DEMANT, P. O mundo muçulmano. São Paulo: Contexto, 2015.

CARTA Árabe de Direitos Humanos, de 22 de maio de 2004. Regulamenta a proteção dos Direitos Humanos Árabe. Disponível em: <http:// adrianaferserol.blogspot.pt/2014/02/arab-charter-of-human-rights-carta. html>. Acesso em: 17 mai. 2017.

DECLARAÇÃO do Cairo sobre Direitos Humanos Islâmicos, de 5 de agosto de 1990. Regulamenta os Direitos Humanos no Islam. Disponível em: $<$ http://adrianaferserol.blogspot.pt/2014/02/declaracao-do-cairo-sobredireitos.html>. Acesso em: 20 jun. 2017.

DECLARAÇÃO ISLÂMICA Universal dos Direitos Humanos, de 19 de setembro de 1981. Regulamenta os Direitos Humanos no Islam. Disponível em: $\quad$ http://www.direitoshumanos.usp.br/index.php/Documentosn\%C3\%A3oInseridos-nasDelibera\%C3\%A7\%C3\%B5es-da-ONU/declaracaoislamica-universal-dosdireitos-humanos-1981.html>. Acesso em: 20 jun. 2017.

IBRAHIM, H. L. O que vestir num país islâmico?. Islam, [online], 24 mar. 2011. Disponível em: <https://amulhereoislam.wordpress.com/tag/ paises-islamicos/>. Acesso em: 16 mai. 2017.

LACERDA, A. F. Educação e direitos humanos para mulheres em comunidades islâmicas. 2017. 206f. Dissertação (mestrado) - Faculdade de Educação, Programa de Pós Graduação em Educação, Universidade Federal do Ceará, Fortaleza (CE), 2017. Disponível em: <http://www. repositorio.ufc.br/handle/riufc/28488>. Acesso em: 16 abr. 2018.

LEITE, C. Ma. F. O Currículo e o Multiculturalismo no sistema educativo português. Coimbra: Fundação Calouste Gulbenkian/ Fundação para a Ciência e Tecnologia, 2002.

MAHMOOD, S. Teoría Feminista y el agente dócil: algunas reflexiones sobre el renacimiento islámico en Egipto. In: SUÁREZ NAVAZ, L.; HERNÁNDEZ CASTILLO, R. A. (eds.). Descolonizando el Feminismo: teorías y prácticas desde los márgenes. Madri: Cátedra, 2008. p. 162 - 215.

NASCIMENTO, C. G. do. Cidadania Planetária e educação. (Cons)Ciência reflexões sobre educação planetária, [online], 02 dez. 2009. Disponível 
em: $\quad<$ http://conscienciaeducacaoplanetaria.blogspot.pt/2009/12/23. html>. Acesso em: 17 mai. 2016.

ONU - Organização das Nações Unidas. Declaração Universal dos Direitos Humanos, de 10 de dezembro de 1948. Disponível em: <http:// www.onu.org.br/img/2014/09/DUDH.pdf >. Acesso em: 23 ago. 2016.

PIOVESAN, F. Direitos humanos e o direito constitucional internacional. São Paulo: Saraiva, 2008.

SANTOMÉ, J. T. Currículo escolar e justiça social: o cavalo de tróia da educação. Tradução de Alexandre Salvaterra. Revisão técnica de Álvaro Hypolito. Porto Alegre: Penso, 2013.

SANTOS, B. de S. Direitos humanos: o desafio da interculturalidade. Revista Direitos Humanos, [online], n. 2, p. 10 - 18, jun. 2009. Disponível em: $\quad<$ http://www.boaventuradesousasantos.pt/media/Direitos\%20 Humanos_Revista\%20Direitos\% 20Humanos2009.pdf>. Acesso em: 28 abr. 2015.

SEN, A.; KLIKSBERRG, B. As pessoas em primeiro lugar: a ética do desenvolvimento e os problemas do mundo Globalizado. Tradução de Bernardo Ajzemberg e Carlos Eduardo Lins da Silva. São Paulo: Companhia das Letras, 2010.

TOHIDI, N. Feminismo Islámico: negociando el patriarcado y la modernidad en Irán. In: SUÁREZ NAVAZ, L.; HERNÁNDEZ CASTILLO, R. A. (eds.). Descolonizando el Feminismo: teorías y prácticas desde los márgenes. Madri: Cátedra, 2008. p. 235-278.

YOUSAFZAI, M.; LAMB, C. Eu sou Malala: a história da garota que defendeu o direito à educação e foi baleada pelo Talibã. São Paulo: Companhia das Letras, 2013.

UN - UNITED NATIONS. Convention on the Elimination of All Forms of Discrimination against Women. 1979. Disponível em: <https:// treaties.un.org/Pages/ViewDetails.aspx?src=TREATY\&mtdsg_no=IV8\&ch apter=4\&lang=en\#EndDec $>$. Acesso em: 16 mai. 2017. 